Working Papers in

Urban Language \&

Literacies

Paper 129

Mandarin Chinese in London education: Language aspirations in a working-class secondary school

Miguel Pérez-Milans

(The University of Hong Kong)

2014 


\title{
Mandarin Chinese in London education: Language aspirations in a working-class secondary school
}

\author{
Miguel Pérez-Milans \\ The University of Hong Kong (Hong Kong SAR)
}

\begin{abstract}
As the Council of Europe is shifting its traditional focus on learning European languages towards emphasizing the importance of speaking other languages of the wider world, an increasing number of schools are offering Mandarin as part of their official curriculum in the United Kingdom. This is being financially supported by transnational/inter-institutional networks headed by Confucius Institutes and linked to the Hanban in the People's Republic of China. In addition, learning of this language is being legitimised by appealing to discourses of "social cohesion" and "internationalism". This article draws from a sociolinguistic ethnography carried out in a London secondary school located in a working-class area. This school converted itself into a Language Specialist School teaching Mandarin when it faced difficulties recruiting the institutionally required minimum number of students for being entitled to receive public educational funding. In the framework of a partnership with the Confucius Institute, which requires affiliated schools to ensure that the success rate of students learning Mandarin meets a given ratio, this paper takes a closer look at the resulting local uncertainties, with a focus on the everyday discursive practices of "collusion" (McDermott \& Tylbor 1986) through which teachers and students create a sense of smooth language learning environment, even when the majority of the students have difficulties in achieving outcome targets.
\end{abstract}

Keywords: Language Policy, Language Ideology, Multilingualism, Mandarin Language Education, Institutional Neoliberalization.

\section{Introduction}

The last decade has seen growing interest among sociolinguists in the effects that contemporary European politics and policies have had on the promotion of multilingualism (Wodak 2007; Lorenzo \& Moore 2009; Krzyzanowski \& Wodak 2011; Moore 2011; Duchêne \& Heller 2012; Romaine 2013). In light of the strategic plans for socio-economic development issued by the European Union (EU, hereafter) since the 2000s, this political perspective and its related policies have paved the way for the production and circulation of new discourses on languages within and across its nation-state members. In a context of changing national, regional and global political economies, sociolinguistic research has identified substantial shifts in ideas and values about language learning and language usage, which seem to have bounced between being emblems of ethnic/national/regional identity and being commodities..

With these shifts, contemporary language education policies in the EU encompass a mélange of guiding principles, among which economic competitiveness, intercultural dialogue, social cohesion and democratic citizenship have been particularly recursive. Indeed, the financial crisis threatening the legitimacy of the EU as a political and economic entity since 2008 seems to be reinforcing both poles of the discursive continuum between "pride and profit" (Duchêne \& Heller 2012). The new policy priorities set out by the current Commissioner for Education, Culture, Multilingualism and Youth constitute an illustrative example of this tendency. Following the enumeration of three major improvements for the education portfolio, namely, help Europe compete globally, equip the young for today's job market and address the consequences of the economic crisis, language learning is being framed in a direct relationship with employability and mobility, as well as with ideas of European cultural heritage (see http://ec.europa.eu/commission_20102014/vassiliou/about/priorities/index_en.htm). 
Existing research has helped reveal these economic, political and discursive conditions but it has not yet shed enough light on the local and institutional dynamics involved in the specific implementation / enactment of policies. Krzyzanowski \& Wodak (2011) and Romaine (2013), two of the most recent studies of EU's contemporary language policies, diagnose a general lack of implementation of the latest policy developments, due to what they consider a loss of momentum of the Multilingualism Portfolio in the midst of financial turmoil caused by the Eurozone debt crisis. However, a close examination of some of the language education policies issued by EU member states in the last few years shows that some of the provisions of the Council of Europe (CE, hereafter) and the European Commission (EC, hereafter) have had specific impacts.

These language education policies include Guide for the development of language education policies in Europe (CE 2007), Recommendation on the use of the Council of Europe's Common European Framework of Reference for Languages (CEFR) and on the promotion of plurilingualism (CE 2008) and Multilingualism: an asset for Europe and a shared commitment (EC 2008). In fact, they have led to widespread implementation of policies lowering the starting age for compulsory foreign language learning in most of the European countries, as stated in the Key Data on Teaching Languages at School in Europe 2012 (EC 2012). This impetus for foreign language learning seems to have contributed to consolidation of the dominance of English in the EU, although in some English-speaking countries such as the United Kingdom (UK, hereafter), it has also led to an incipient institutionalization of Non-European languages. Indeed, this has been interpreted by some commentators as a shift away from the traditional promotion of teaching/learning of European languages within and across its member states, which had resulted from a traditional Eurocentric/Western-based international order characterized by its insensitivity to any connection between language learning, mobility and global communication, towards a new policy framework that now places more emphasis on dissemination of the languages of the wider world (Fenoulhet \& Ros i Sole 2011).

Against this background, a key set of questions, particularly relevant for sociolinguisticrelated enquiry, emerge: how are these other languages of the wider world being institutionalised and localised in the everyday, situated life of particular school communities? What official and non-official discourses are mobilized at these schools to make sense of the teaching and learning of these languages? How does the implementation of such languages affect the socio-linguistic order of the schools? How do the social actors involved in language learning/teaching position themselves and others in relation to these other languages of the wider world? What interests and motivations are there for the students to learn such languages? With the aim of answering these questions, the present article draws on a sociolinguistic ethnography carried out at a London secondary school implementing Mandarin Chinese as part of its official curriculum.

The close examination of the school constitutes an illustrative case study of how a language of the wider world is locally implemented, in line with the contemporary language policies of the EU. I begin by providing brief contextualization of the teaching of Mandarin in the UK (Section 2) and then outline the main theoretical, methodological and analytical perspectives that guided the data collection process (Section 3). After that, Section 4 describes the story emerging from the research, with focus on the tensions and dilemmas at the level of the school (Section 4), the Chinese division (Section 5) and the Chinese classes (Section 6). Finally, Section 7 discusses the implications of the data for understanding language-in-education policy and practice under conditions of late modernity, drawing on the perspective of the sociolinguistics of globalization. 


\section{Mandarin and foreign language education in the UK}

The wider ideological and policy shifts of the EU that have been outlined in the beginning of this article can be easily tracked in the context of language education policies issued in the UK in the last few years. These shifts have resulted in the emergence of new discourses of "community language learning" which go beyond the traditional "foreign language learning" to refer specifically to minority languages (McPake, Sachdev, Carroll \& Mukadam 2008: 5$6)$. The emergence of this discourse of "community language learning" is reflected in two main lines of action.

First, the government has recently abolished compulsory foreign language teaching for students aged 14-16.

Second, the shift is giving rise to governmental and non-governmental initiatives aimed at enhancing links and partnerships between mainstream schools and complementary schools run by local minority communities oriented towards the teaching of their respective heritage cultures and languages (see The National Centre for Languages:

http://www.cilt.org.uk/home.aspx). These initiatives are aimed at promoting social cohesion and community cohesion in cosmopolitan and culturally/linguistically diverse cities such as London. In this way, they are officially oriented towards teaching students' home languages and enabling a deeper understanding of their heritage languages and cultures.

However, these values are not solely articulated in the institutional push to community language learning. The economic or instrumental value of minority languages is also fuelling the debate, as new official surveys in the UK reflect a continuing downward trend in the number of students studying languages in compulsory education, indicating a lack of interest in the traditionally institutionalized languages in Europe (i.e. French or German) (CILT 2005, 2008, 2010):

"Many of the benefits which modern languages specialists recognise in students who gain competence in languages, such as French, German or Spanish, apply equally to those who speak community languages, such as Urdu, Chinese or Greek. These include increased awareness of an interest in the wider world, greater confidence in communicating in a range of different contexts, enhanced understanding of cultural differences and a willingness to engage with people and ideas from elsewhere in the world. These are personal qualities of value in themselves, but also are clearly of considerable worth in a business context" (CILT 2005: 1).

These economic values have been emphasized in the latest reports published by the British Council, an institution that plays a key role in the development of language education policies in the UK. After a foreword, in which the Director of Strategy of the British Council urges people in the UK to learn a much wider range of languages, going beyond French, Spanish and German and to Arabic and Mandarin Chinese (among others), the Languages for the Future Report published in 2013 aligns with the EC:

"Studies for the European Commission have shown that the economic benefits of competence in more than one language are not limited to English. A wide range of languages are needed to exploit the benefits of the single market and keep improving trade between peoples worldwide. Even when others have a high level of proficiency in English, this does not mean that their languages can be ignored. In order to develop relations between countries and individuals based on mutual respect and trust as well as to do business effectively, there is a need for an understanding of the social, political, and technical systems of a country, as well as the innumerable aspects of daily life that are 
important to that nation's identity and culture. Of course people learn languages for more than purely instrumental purposes, but learners do want to be able to use the languages they have learned, and taxpayers and governments want to see their education resources spent in a way that will provide the greatest possible long-term benefits" (Languages for the Future Report 2013: 4).

This line of reasoning has also been echoed in public speeches by politicians in the UK. In December of 2013, for instance, the Prime Minister, David Cameron, urged British youngsters to ditch French and learn Mandarin:

"By the time the children born today leave school, China is set to be the world's largest economy. So it's time to look beyond the traditional focus on French and German and get many more children learning Mandarin" (The Guardian, Thursday 5 December 2013).

The increasing value attributed nowadays to Mandarin Chinese in the UK has led to a partnership between the British Council and the Confucius Institute Headquaters (Hanban) the Chinese National Office for Teaching Chinese as a Foreign Language - with the aim of offering Mandarin as a language option in the curriculum of primary and secondary schools.

According to the Confucius Institutes network, this partnership had set up 23 Confucius Institutes and 60 Confucius Classrooms across major cities in the UK by the beginning of 2013. Among these, the Confucius Classrooms, which were initially coordinated by the Specialist Schools and Academies Trust (SSAT) and later transferred to the Institute of Education in the University of London (Zhu Hua \& Li Wei 2014), are committed to teaching Mandarin and about China across the curriculum, and are able to access funding through the Confucius Institute to support their development (http://english.hanban.org/node 10971.htm).

Beyond this official narrative, existing literature does not seem to provide a clear picture of how actors in the involved schools deal with the situated implementation of teaching and learning of Chinese in the curriculum. Previous research has explored how this is done in complementary schools (Blackledge \& Creese 2010, Li Wei 2013) or tertiary education (Li Wei \& Zhu Hua 2013), and some very recent work has also provided in-depth description of the discourses and ideologies mobilized by different stakeholders to make sense of the spread of Mandarin teaching across Britain (Zhu Hua \& Li Wei 2014). However, the space of the institutionalized implementation of Mandarin in compulsory education is still under-studied from the perspective of ethnographic-and-discursive research. The following sections shed further light on this, although it is worth explaining first what this approach entails.

\section{Approach, site and data, through the lens of sociolinguistic ethnography}

The fieldwork reported here involved the initial exploration of a secondary school in London (April-May, 2011), as part of an ethnographic and discourse-based multi-sited research project that is expected to be expanded to cover more schools and participants across London and Hong Kong in due course. ${ }^{1}$ In this regard, the focal school that I selected is an illustrative case of an institutional site implementing a Mandarin language education policy, which in

\footnotetext{
1 This research was funded by the Programa de cooperación con Asia de la Universidad Autónoma de Madrid y el Banco Santander (2011-2012) of the Autonomous University of Madrid through the project "Chinese and English as Languages of the Wider World: a Sociolinguistic Study on Second Language Education and Youth's Interests in London, Madrid, and Hong Kong", in addition to the complementary funding received from King's China Institute at King's College London. As participants of this funded project, this article has benefited greatly from comments and feedback given by the following colleagues during research data analysis sessions: Hsin-Yu (Chris) Chen, Marco Pellegrinelli, Ben Rampton, Luisa MartínRojo, Constant Leung, Roxy Harris, Li Wei. Needless to say, the misapprehensions are mine.
} 
turn is derived from the wider national and supranational language policies and ideologies discussed in the previous sections. Thus, the choice of the research is based on an understanding of school as an institutional space in which situated social action is tied into wider discourses and social practices that take place in remote spaces/times, beyond the school's walls (Heller \& Martin-Jones 2001).

That is to say, my methodological choice rests upon an ontological view of social institutions as spaces in which local forms of knowledge, practice and social categories are linked to translocal processes of social organization (Cicourel 1973, 1980, 1992; Smith 2005; Heller 2007; Martín-Rojo 2010; Pérez-Milans 2013). Thus, and following Heller (2007), the fieldwork attempted to follow the web-like trajectories of the socio-ideological, institutional and interaction orders of the focal school (including the linguistic and the moral orders) in order to comprehend how and why this institution got discursively configured at the intersection of the policies/discourses of British Council, EU and Hanban.

In accordance with such ontological and epistemological positions, data collected include field-notes (69 pages), interviews with teachers (6) and students (7) in the Chinese division, questionnaires completed by students in year 10 and 11 (22), classroom interactions in the Chinese classes of year 10 ( 5 hours) and lesson materials used by participants in the observed classes (30 sheets), as well as institutional documents on language education produced and circulated in/about the Chinese division. The triangulation of these different sources aims to capture the discursive work on which every institution is constituted as a product (linguistic, cultural, economic, socio-political and moral) of its own trajectory in time and space (Berger \& Luckmann 1991; see also Roberts 2009; Sarangi \& Slembrouck 1996). More specifically, and in line with Heller (2007), I consider the analysis of this discursive work to be a window into the study of how actors engage in a great deal of discursive and ideological production to legitimise the sheer existence of the organisation, its mission and social goals, as well as the identities and social/moral categories that emerge and are constructed/negotiated out of institutional processes (i.e. what counts as a "good school", "good division", "good participant", or "appropriate forms of knowledge).

In doing so, my analytical pursuits are also driven by an interest in capturing interpersonal dynamics that fall beyond modernist accounts of institutions (Rampton 2006). At a time when the state has lost its monopoly over the definition of what counts as the legitimate language, culture and identity, public institutions are redefining their social function, away from their traditional role in the production of citizens aligned with the "one people-one culture-one language" discursive imagination of the modern nation-state. Thus, the exploration of social life in these spaces also has to be informed by a close look at the creative forms of meaning-making through which social actors deal with their local circumstances, considering the increasing degree of uncertainty and instability that has been associated with the socio-economic, cultural and institutional conditions in the age of late modernity (Harris \& Rampton 2009, Blommaert \& Rampton 2011).

\section{The East London Secondary (ELS) school}

The last issue of the school magazine published in 2010 opened its contents with a section on a talk given at the school by a UK member of parliament for the area in which ELS is placed:

"In [name of the district], social mobility has been closely linked to actual mobility. If you were doing well, you moved out usually eastwards. That is dramatically illustrated whenever West Ham plays at home, and thousands of people stream in to Upton Park from further along the District Line. We have a chance to change that now. With the 
Olympic Games, people will be attracted towards [this area], instead of wanting to move away (...) we will be linked to aspiration, to high achievement. It's a chance for our area to be a place where you can aspire and achieve and still put down roots (...) Social mobility has a lot to do with economics. Our economy will do much better in the future if the people in top jobs are those who deserve to be there, than if they were simply those who were born into privilege" [School's magazine, $\mathrm{p} 4$ ].

At the time of data collection, London was getting ready for the Olympic Games, an international event in which the mobilization of billions of US dollars and economic interests of hundreds of service-based transnational corporations was discursively linked to social justice (http://www.olympic.org/). In this regard, ELS, a state-funded comprehensive community school in the working class area of East London, became a local index of the spirit of the Olympic Games.

The school is located in an area inhabited by a demographically changing population shaped by the contemporary migration patterns in the UK. In 2012, the top occupations of the population in this area involved low-income elementary jobs. According to the official statistics, $51.8 \%$ of the residents were not born in England and the most predominant nationalities were, in decreasing order: Nigeria, Bangladesh, India, Pakistan, Ghana, China, South America, Hong Kong and Somalia (UK national statistics 2011). These demographic features permeated the socio-economic characteristics of the population at ELS, which hosted a total number of 1,450 students aged from 11 to $16,65.3 \%$ of whom were stated to speak a first language other than English.

The school's institutional documents show that the vast majority of these students were categorized as of low socio-economic background, and indeed $63 \%$ of them were entitled to free school meals - the school was officially ranked as "high free school meals eligibility band". As shown on the school's website, the Educational Destination Measure for the 2009/2010 cohort in the school indicates that the students who finished Form 4 that year had taken further vocational education (32\%), Sixth Form college/school (54\%), or no further education at all (18\%), although by 2013 none of them had been enrolled yet in any UK higher education institution.

ELS was founded in 2000, and after a few years of struggle to get an appropriate in-take it became a Specialist Language College by establishing partnerships with various private sponsors such as the Hong Kong Shanghai Banking Corporation, which also allowed the school to have access to additional government funding. ${ }^{2}$ Since then, the school has been offering French, Spanish and Mandarin as the available choices for students who are required to take their General Certificate of Secondary Education (GCSE) in one of these three languages. Among such languages, the teaching of Mandarin has given ELS a unique reputation in the UK and beyond, since the school was one of the first to receive the Confucius Classroom status ${ }^{3}$ in the country. The Head Teacher of ELS gives an explicit account of this, in the introduction of the school's magazine:

"The last academic year was without doubt one of the most memorable in the school's history and indeed, has culminated in the school achieving its best ever GCSE results,

\footnotetext{
${ }^{2}$ In the UK, the Specialist Schools Programme helps schools to develop identities through their chosen areas of specialisation. Specialist schools focus on their chosen subjects, providing enhanced learning opportunities in the particular fields; they must also meet the requirements of the National Curriculum, to deliver a wide and balanced range of subjects. There are twelve specialist areas: arts, business \& enterprise, engineering, humanities, language, mathematics \& computing, music, science, special specialism, sports, technology and vocational.

${ }^{3}$ In 2007, the school became the first Confucius Classroom, a recognised centre for promoting Mandarin Language and Chinese Culture, in London and the South-East. Subsequently, the school has worked closely with Hanban (the National office for Teaching Chinese as a Foreign Language) in order to develop its own Chinese learning programme and also to promote the teaching of China's language and culture to other schools in the capital and South-East region.
} 
with over $65 \%$ of students achieving $5 \mathrm{~A}^{*}$ to $\mathrm{C}$ GCSe grades (...) The last academic year was also an extremely successful one for the Languages curriculum which continues to flourish at [ELS]. Recent reports have noted the decline in Languages in UK schools, following the decision to stop modern foreign language being compulsory at GCSE level. As a Specialist Language College, [ELS] has recognised the need to support and promote language learning, knowing that the skills acquired can open doors for students in their future lives (..) I am also absolutely delighted to announce that [ELS] has been reaccredited with the International School Award for 2010-2013 (...) The school has recently welcomed many important international visitors, including Madame Xu Lin, Director General of Hanban, who declared [ELS]'s Confucius Classroom to be one of the best in the world. [ELS]'s achievements continue to gain recognition at the local, national and international level. The school's recent success have gained significant press coverage and the school also hosted many notable figures, not least for the 100 Group Conference, which resulted in the school being praised by then Prime Minister for its unique link with [CAP], one of country's independent leading schools" [School's magazine, p. 3].

In a discursive context traversed by the combination of social cohesion and economic instrumentalization of global languages such as Mandarin, emphasized locally in the UK and regionally in the EU, implementation of the Confucius Classroom at ELS has become a key form of capital for the school. The teaching of Mandarin constitutes added value in the public display of its image as a model institution, or "good" school, which is closely related to the building of a narrative of active engagement in competitions, rankings, internationalization and academic excellence. In fact, the national and international recognition of such an image, via awards and press coverage, has played a fundamental role in the establishment of a partnership with one of the most prestigious sixth form colleges in the UK, as part of a wider strategic plan intended to provide students from leading schools in East London with a door to higher education. At an interview published in the magazine of London Institute of Education, which was later displayed by ELS on its own brochures, the Language College director referred to the symbolic nature of having the Confucius Classroom in a school like ELS:

"There are several Confucius Institutes in universities - there's one in the School of African and Oriental Studies - but [ELS] was the first in the world to be called a Confucius classroom, recognised as such by the Specialist Schools and Academies of Trust (SSAT) in collaboration with Hanban, the Chinese equivalent of British Council, and Peking University. There are others now, but a number are grammar or single-sex independent schools. 'It's key that we're a comprehensive, mixed, east London school in one of the most deprived areas of London"' [London Institute issue 12, p.8]

It is precisely the major symbolic profile of the Mandarin programme at ELS that set up the framework for the specific dilemmas faced by teachers and students in daily practice. These are analyzed in detail in the following sections.

\section{The Chinese division at ELS: tensions and dilemmas}

As one of the first educational institutions to teach Mandarin in the UK, the Chinese division at ELS has been well consolidated. In contrast to other schools, where the divisions in charge of teaching Mandarin consist of just one teacher, this one has four permanent teachers plus 
three Hanban teachers sent from Mainland China annually. However, exploration of the daily life in this division revealed from the very beginning the consequences of the importance assigned to the Confucius Classroom in the school. All actors involved in the Chinese division are put under great pressure to make the implementation of Mandarin a successful experience, in a context where so much is at stake for the whole school community.

Extract 1. "This opportunity to get extra sponsorship" \{Focus group with students in Year 11\}

Miguel: what about you? / ((what's the role of Chinese)) in the place you live?

Gisela: I think / outside [ELS] community / most people are / prejudiced against Mandarin / because they see it as too difficult $\uparrow$ / so they just ((drop out)) \&

Miguel: \& ok \&

Gisela: \& but I think slowly day by day / while breaking out the barriers / that's why (( )) the school / majority of the school's sponsorship- sponsorship / comes from Mandarin based (( )) like Hanban / which is very good / so I think if these schools recognize this opportunity to get extra sponsorship as well as recognition for this language / it will break down the whole prejudice / and / allow Mandarin to flourish as well

As stated by Gisela, a Year 11 student in the Chinese division (aged 15-16), everyone in the school was aware of the specific value that Chinese had for the school community as a whole. All teachers and students knew the Chinese division imparted a unique dimension to the curriculum and to the school at large, particularly in terms of attracting funding, media attention and recognition from other educational institutions. Nevertheless, daily implementation of Mandarin has not been free of paradoxes. The division allowed the school to engage with narratives focused on competitions, rankings, internationalization and academic excellence which had consequences for the institutional categorization of the school as a "good school". But at the same time, the Mandarin section was caught in a process of redefinition at the intersection of two overlapping logics.

On the one hand, the Chinese division had to adjust to an ongoing competition over student recruitment with other divisions in the school, in line with the existing logic of the way second language learning is viewed in the UK, with the subsequent struggle over which division and which students are counted as the best. On the other hand, the Chinese division also had to conform to the expectations and obligations emanating from the partnership between the British Council and the Hanban office. More specifically, due to the extra funding that was involved, it had to manage the ensuing struggle over the definition of what counted as the most appropriate forms of teaching and knowledge in the classroom activity.

\section{French vs. Mandarin}

The initial excitement linked to the implementation of a new global language like the Chinese, in a working-class school like ELS, soon gave way to the normalized routine of a symbolic space, or sociolinguistic market, in which French still retained a privileged position. In the UK context, French has occupied the historical position of being the preferred second language, particularly in the space of institutionalised education in schools where this has been the common option for foreign language learning. Thus, a "newcomer" such as Mandarin has to fit into this established normative framework. Jason, a British teacher of the Chinese division, details the specific ways in which this institutional disadvantage worked in ELS:

Extract 2. "It's a battle between the French teachers and the Chinese teachers" \{ Interview with Jason, Mandarin teacher $\}$ 
Miguel: soo / what are their motivations / for choosing / Mandarin? / [what do you think are their interests in learning Mandarin]

Jason: [uuh / you hear- a lot of it is uh] // parents' recommendation / a lot of times I hear my students say / uh / my mum says this is very important / but a lot of think this is fun and different $\uparrow /$ and / it's important as teachers we try make it as exciting as we can / because well in this school we choose French or Mandarin / so / it's a battle between the French teachers and the Chinese teachers \{laughs $\}$ (...) the only issue in the school is that / if they are good at French / they go into fast track French / which means that they complete the GCSE in three years // so- and so if they do fast track French they can't do Mandarin / $\mathrm{hm}$ - the problem is- in year 7 they can go into fast track / and / I find / it's- it's not the students who are good at French who go in the fast tract / it's just the students who work hard / go on fast- and so all of my strong Mandarin students / they are strong / not because they are fantastic at Mandarin but because they work hard / and so a lot of them get taken to do / GCSE in French / so that's an issue

Although French and Mandarin represent two different paths offered by ELS, these two languages do not have the same specific value. The fact that doing a "fast GCSE track" mode applied to only French had the consequence that the French division was in a privileged position to take the best students in the school. In other words, Mandarin did not have an equal institutional status since many students took this choice only when they failed to get into the French division. Under these conditions, the Chinese division had to produce a substantial mass of official propaganda to compete with the French division in order to attract students - at least those who were not selected for the fast track.

In so doing, they appealed to the major discourses widely circulated in the UK and beyond (see Section 2 above) where Mandarin is closely tied to values emphasizing: a) an exit point from the European languages that have been traditionally institutionalized in education; and b) a door to an increasingly internationalized job market where China plays a fundamental role. Extract 3 illustrates the rationale of contrast with the European languages, as constructed by the Head of the Chinese Division during a conversation on the cultural attraction of Chinese:

Extract 3. "We need to get as much out of that as possible in these years" \{Interview with Aaron, Mandarin teacher and Head of the Chinese division

Miguel: in the questionnaires that I conducted to the students I found this interest in the culture when they referred to the reasons why they chose Chinese

Aaron: yeah / it's a strong attraction / isn't? / French / Spanish and other / more / traditional / foreign languages // we've moved / to a period of time where / we can still study the culture // Spanish / French speaking culture // uh / but it doesn't have the same attraction as / Chinese / background / culture // still have a / sense of / exotic / culture to- behind the Chinese language / and we- we need to / get as much out of that as possible / in these years

Cultural exoticism constituted a key strategic line of action during the first years of the implementation of Mandarin. This attribute helped reinforce the polarization between traditional European languages and Chinese which, in line with an orientalist ideological framework (Said 1978), provided a platform to attract the students. This was a recursive discourse at ELS, where the Chinese division was linked to a pre-modern cultural aesthetic that offered an alternative experience of language learning. Figure 1, for instance, shows the visual elements displayed in the school's brochure, where the Chinese division is distinguished by its framing in relation to ancient cultural activities and practices such as taiqi, in contrast with the more contemporary emblematic images of the Eiffel tower and fashion outfits used to represent the French division. 
Figure 1. Language and culture at ELS
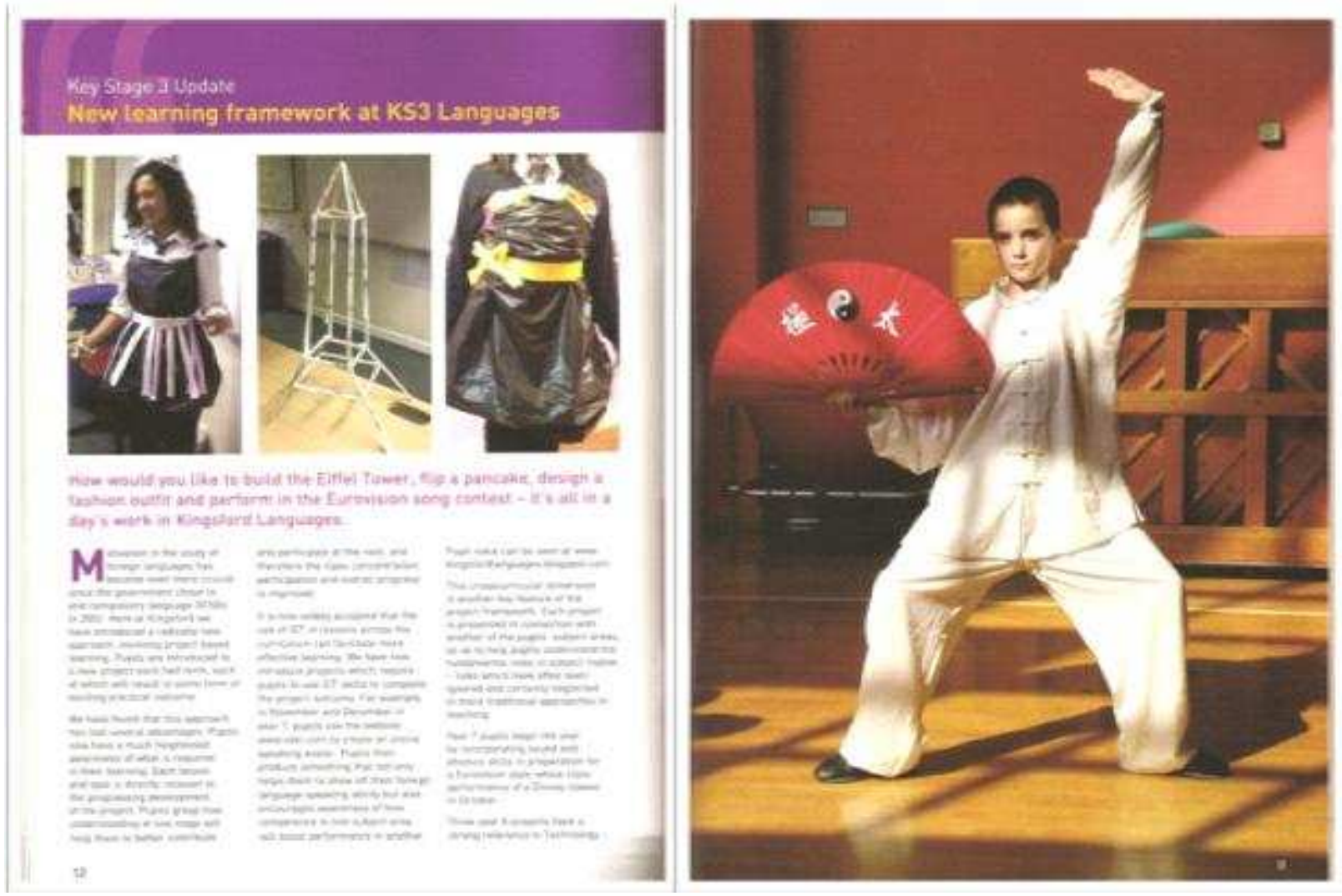

Promotional brochures produced by the Chinese division emphasized that the Chinese language has become a door to an internationalized job market increasingly dominated by China. For instance, specific figures showing the numbers of employers looking for Mandarin speakers in the UK were given. In one of such brochures, the figure was accompanied by a brief quote from an interview with the Head Teacher of the school in which she stated:

"We realised that China was going to be massive in terms of the global economy with huge impact on the Western world. An extra benefit is that most of the students in this area don't know Mandarin at all, so everyone was starting on a level playing field" [Brochure by the Chinese Division]

The importance of Mandarin in this context also emerged from the questionnaires and focus groups conducted with the students in the Chinese division. Table 1 below shows a summary of the recurrent points made by those in Years 10 and 11. The main motivations to learn Mandarin included their desire to display the social image of students oriented to difference, challenge, commitment to language learning, ability in bridging knowledge with the most advanced economies, openness to cultural experiences, academic distinction and cleverness. As a whole, these motivations and forms of making sense indicate the ways in which the official values publicly performed by the school and the Chinese division contributed to the definition of a good student in a language specialist school like ELS. 
Table 1. Students' motivations for learning Mandarin

\begin{tabular}{|c|c|}
\hline Motivation & Extract \\
\hline $\begin{array}{l}\text { More fun and impressive } \\
\text { than other languages like } \\
\text { Spanish or French }\end{array}$ & $\begin{array}{l}\text { "It's just that the other subjects- other languages / don't impress me } \\
\text { // like / French Spanish / I don't know / I think it's because they use } \\
\text { English words or something" }\end{array}$ \\
\hline Challenging & $\begin{array}{l}\text { "I really like challenges / I could've picked }(()) \text { French and } \\
\text { Spanish / aand / Mandarin }(()) \text { I find it fascinating" }\end{array}$ \\
\hline $\begin{array}{l}\text { Gives you an extra grade to } \\
\text { find a job as it shows } \\
\text { commitment to different } \\
\text { languages }\end{array}$ & $\begin{array}{l}\text { "I just find it / like / Mandarin gives you / a significant / like / it's / } \\
\text { like / significant (grade)? / it's not because it is a grade / like / like / } \\
\text { you go into a company / and you try to get a job / it's not / they don't } \\
\text { look always for / like GCSEs and A levels } \uparrow \text { / but they always see } \\
\text { how commit you are to different languages / and the fact that- } \\
\text { because Mandarin is like the ((hardest you can choose }) \uparrow / \text { and the } \\
\text { fact you can pass it / sounds that you are really commit to it } \uparrow "\end{array}$ \\
\hline International asset & $\begin{array}{l}\text { "China is the most develop- it's not the most develop / it's the most } \\
\text { economically stable / that's what the }(()) \text { is / the fact that you can } \\
\text { learn the language to bridge the barriers between the country which } \\
\text { is the most economically stable and the rest of the world / I think } \\
\text { that's ((makes it)) impressive" }\end{array}$ \\
\hline Cultural experience & $\begin{array}{l}\text { "uh / I think there is / as }(()) \text { you can learn the culture / ( ( )) be } \\
\text { able to live in the country / uh / so when you develop your Chinese } \\
((\quad)) \text { they can understand you easily / (( )) communicating with } \\
\text { the world / so when you go to China / you can deal with it and have } \\
\text { a good experience" }\end{array}$ \\
\hline Academic distinction & "Set me apart from candidates for university placement" \\
\hline Display of local identities & "to make me seem smarter" \\
\hline
\end{tabular}

\section{Chinese teachers, standards and tests}

In addition to the logic of competition in recruitment, the funding from Hanban imposed further dilemmas and tensions on the Chinese division. Vested with its own agenda and policies, the joy of being a Confucius Classroom involved a series of obligations tied with the overarching and transnational structure of the Confucius Institute. Among these, making room for visiting teachers from Mainland China and meeting specific learning standards became a central issue at ELS. Regarding the visiting teachers, the partnership between the British Council and Hanban included the provision of visiting teachers over periods of one year, during which they had to contribute in flexible ways, depending on the local circumstances. Although this was often represented as an opportunity for cultural exchange at ELS, it also constituted room for complications concerned with differences in teaching styles and expectations, as explained by Jason in Extract 4.

Extract 4. "It's quite difficult for Chinese teachers to just to succeed in English schools" \{Interview with Jason, Mandarin teacher\}

Miguel: I heard that Hanban teachers / get training before coming here to- United Kingdom / right?

Jason: yeah \&

Miguel \& a training in British education system / and methods / [everything] =

Jason: [yeah]

Miguel: $\quad=$ because there was- there was a huge difference 
Jason: yeah / but it's still very / it's still very difficult for them // uh / yeah / specially in this school $\{$ laugh $\}$ it's very \&

Miguel: $\quad \&$ yeah \&

Jason: \& I mean / there are so many benefits to be native English speaker teaching in English schools $(())$ / just an understanding of where the students are coming from / because culturally Chinese is so different / it's quite difficult for Chinese teachers to / just to succeed in English schools / in my previous schools they had a lot of problems // they're always gone through Chinese teachers / uh / here as well as have quite high turn over of Chinese teachers ((and for students)) it's such a shock / and it's so difficult / uh / and I think that the expectations are too / too high / for the students progress / it's sound bad to say- we have high expectations / kinda realistic high expectations // like an average I try to introduce like / like six new words / a lesson $\uparrow$ / the highest / and that's quite a lot / still / for the students / with their characters / tones / and stuff / but I think / before / when we used the textbook / one lesson you might have / like / twenty words

In line with what has been described elsewhere, regarding the predominant teaching methods in the People's Republic of China (Cortazzi \& Jin 1997; Pérez-Milans 2013), the classes taught by these Hanban teachers at ELS used to rely on forms of choral repetition around the key vocabulary items and sentences of each unit lesson. Many students in the Chinese division complained about this. They stated that this teaching style was too mechanical and boring and that expectations were often very high in terms of number of characters that they were expected to learn. Indeed, there seemed to have been a change in the distribution of roles: in contrast to the past, the Hanban teachers were being assigned extracurricular activities and forms of contribution more focused on a cultural dimension. The Head of the division explains it in Extract 5: Hanban teachers are placed as providers of the cultural distinction often linked with the Chinese division.

Extract 5. They help massively in extracurricular activities \{ Interview with Aaron, Mandarin teacher and Head of the Chinese division \}

Miguel: and what is the situation in terms of the collaboration between the British teachers of Chinese and the Hanban teachers?

Aaron: yeah / they are assistants / depending of the context / they will be given different levels of responsibility / in our context / in our context / is / very much / the case (2") that they offer supportive roles in our school // in other schools they might be quite independent in classrooms / uuh / and here they've been to some extent too / but now / they help massively in extracurricular activities / and in the general profile of Chinese across the school / because they bring that cultural dimension / I can organize things as well / as an English man / along the Chinese uh / lines of culture / but it's not the same / as a real Chinese teacher being over here for a few months and saying / this is what we do for Chinese New Year / and that's very important for the / motivation / and engagement / of children / in their studies

The funding from Hanban entailed other obligations related to the specific learning standards. These required ELS to evaluate Chinese learners' progression through a set of standardized tests prepared and closely monitored by the Chinese agency. In line with the partnership between British Council and Hanban, schools offering the Chinese track for the GCSE have to fulfil a minimum rate of success to keep the funding going, measured as a percentage of students who pass the final tests at the end of Form 5 (Year 11). This pressure was even higher for schools such as ELS who held the status of a Confucius Classroom in that they played a model role for other educational institutions to follow.

In the context of competition with the French division, a constraint like this posed a serious threat to the survival of the Chinese Division. The requirements imposed by the 
Hanban office clashed with the official discourse on the learning of Mandarin displayed at ELS. Rather than making it fun and enjoyable, the standards policy introduced by Hanban demanded a high degree of memorization of characters in a relatively short period of time (3 hours per week throughout 5 academic years). Indeed, this concern gained weight at the time of data collection because the first cohort of students who started the Chinese track in Year 7 was soon to take their final GCSE test.

As a result of this increasing concern, teachers in the division decided to introduce in their classes a more explicit balance between, on the one hand, an emphasis on characters memorization and on the other, the development of what they called "learning strategies", meaning the design of activities that help students to use mnemonics in order to make memorization less difficult. In addition, they had also agreed on expanding their offer in order to keep the interest of students who were not able to deal with the institutional pressure of preparing for the GCSE, as explained by Aaron in Extract 6 when commenting on the long term future of Mandarin.

Extract 6. "It would be useful to picking up students who are sort of borderline" \{Interview with Aaron, Mandarin teacher and Head of the Chinese division\}

Miguel: what is the future at long term of these kinds of initiatives / like / teaching Mandarin Chinese through compulsory education? / is there a future in this \&

Aaron: \& do you mean within our school or nationally?

Miguel: well / both

Aaron: within our school / eh / we hope that / more and more students will take Chinese / uh / because all of the year seven / the young students (...) will take Chinese for one year // we hope always to keep the profile very high ((for)) Chinese (...) uh / Chinese in our schools gives us a- a very unique dimension (...) to the curriculum and to the school at large / something which attracts a lot of attention from the media and other educational institutions // we hope to / you know / keep the numbers / taking GCSE (...) high // (( )) to go even higher (...) uh / then / also / another hope that we have / is / uh / I think / putting more the business dimension (...) on the Chinese study (...) at the moment we are developing a- a new Chinese course called MBQ / MBQ / in Chinese / and this course is very much targeted towards operating in business / using languages / we believe that would be a very useful course / if ((it)) existed / and / uh / students who may not \{cough \} feel so comfortable / academically / with the challenge of Chinese / which of course (( )) GCSE being academic standard / MAY / be more comfortable taking the MBQ / which is designed completely different / with individual assessment as they go along / and which / uh / has / (( )) it has no exams / at the end of the time / and we believe it would be useful to / picking up students who / are sort of borderline / not necessarily happy with GCSE

Miguel: but that would be a / curricular subject?

Aaron: yeah / it would be on the curriculum

Although the media attention was helping the school to enrol students taking the GCSE in the Chinese track, there was an increasing awareness among the teachers in the Chinese division that high degree of pressure to meet the academic standards was a challenge for many of their students, which in turn jeopardized the legitimacy of the division. Thus, at the time of data collection, the school was considering alternative programmes such as Chinese for business purposes that would allow the Chinese division to cope with this tension by offering a nonacademically oriented path which did not require the GCSE standards. In this way, the Chinese division was adjusting to a school population that was not academically strong, because of competition with the French division, through diversifying and expanding its offer beyond the GCSE standards. 
All of these tensions and forms of adjustment were not only played out in the form of decisions taken by teachers and heads at the level of division/school but were also locally enacted and negotiated by the teachers and students involved in the Chinese classes.

\section{The Chinese classes}

The recurrent organization of the unit lessons in the observed classes seemed to follow a pattern that allowed the participants to deal with the major concerns discussed in the previous sections. Although each unit lesson across all divisions in the school was arranged around the key curriculum areas for language learning (listening and responding; reading and understanding; and writing), the Chinese division focused on the principle of highly controlled designs, with the aim of maximizing the opportunities for the students to become familiar with the key vocabulary items of the final examinations. Extract 7 shows a representative example of this type of pedagogical scaffolding, corresponding to a session towards the end of the unit called "My area", in which the teacher, Aaron, has his students work in groups around a worksheet on writing that he had specifically designed for them. During the activity, the audio-recorder was placed next to one of the groups whose members are shown in Table 2.

Table 2. Focal participants in Extract 7 (taken from the school's data)

\begin{tabular}{|c|c|c|c|c|}
\hline Name & Ethnicity & Home language & $\begin{array}{l}\text { First } \\
\text { language }\end{array}$ & $\begin{array}{l}\text { Mandarin } \\
\text { Interim } \\
\text { grade }\end{array}$ \\
\hline Tessa & $\begin{array}{l}\text { White } \\
\text { Eastern } \\
\text { European }\end{array}$ & Lithuanian & Lithuanian & $\mathrm{D} / \mathrm{E}$ \\
\hline $\begin{array}{l}\text { Assya } \\
\text { Eva }\end{array}$ & $\begin{array}{l}\text { Pakistani } \\
\text { White } \\
\text { Eastern } \\
\text { European }\end{array}$ & $\begin{array}{l}\text { Urdu } \\
\text { Lithuanian }\end{array}$ & $\begin{array}{l}\text { Urdu } \\
\text { Lithuanian }\end{array}$ & $\begin{array}{l}\mathrm{D} \\
\mathrm{C}\end{array}$ \\
\hline Paola & $\begin{array}{l}\text { Black - } \\
\text { Nigerian }\end{array}$ & Yoruba & Yoruba & $\begin{array}{l}\text { (started this } \\
\text { year) }\end{array}$ \\
\hline Sharon & $\begin{array}{l}\text { Black } \\
\text { Caribbean }\end{array}$ & Creole (English) & English & $\mathrm{D}$ \\
\hline
\end{tabular}


Extract 1. We are good in Mandarin! \{Classroom interaction, year 10\}

(...) $\left\{2^{\prime} 42^{\prime \prime}\right\}$

Aaron: I need you to start thinking ((through these things)) guys // you are going to be in year 11 soon / ((you got a lot to take on)) / forget/ soon / right no:w! / you've got to ((consider)) yourselves in year $11 /((\mathrm{so}))$ a final stretch towards the exams (4") you've got to get in the mentality of organizing yourself // don't wait / for teachers to ((he:lp)) you / ((chase around you after school)) / you've got to get in the mentality of / diligent preparation for your exams (...) // I need you to switch on / so that means today's lesson / is about ((hands off)) lessons in terms of ((sir and me)) / you've got independent ((preparation to do)) / you've got / a lot of work to do / (()) // let me show you one final resource that I've prepared // ok? / for those of you // for those of you who really are not confident of your materials / prepare this one / it's just like / the book that I already gave you / but / on this one // ((I completely tee up for you )) / still needs (()) your work $\uparrow$ / your own ((tense)) / but in each case / you fill in the gaps ((that are completely)) empty // there are no excuses now // the aim of today's lesson / by Friday /

(...) $\left\{166^{\prime} 48^{\prime \prime}\right\}$ you should get these gaps filled / have your text ready

Tessa: we should give each other code names

Assya: (yeah) ${ }^{\circ}$

Tessa: ok / I'll be \&

Eva: Smigua \&

Tessa: no I don't (()) / I'll be \&

Assya: \& (()) \&

Tessa: \& I- I'll be \&

Eva: \& (()) \{laughs $\}$

Tessa: ok / so what are you gonna be?

Eva: I'll be ((dijui))

Assya: what?

Tessa: ok / I'll be ((Beatrice))

Paola: ok / ASSYA

Tessa: you're dijui // Eva / you can be \&

Paola: \& why ((are you using her name?))

Assya: the name $\{$ laugh $\}$

Tessa: ok / I take that one / ok

Assya: (( )) \{laugh $\}$

Tessa: ok // me \&

?: \& shh

Tessa: yeah you / shh/

Assya: you $\{$ laugh $\}$

Tessa: you'll be \&

Assya: \& t! \{laugh\} // you'll be t $\{$ laugh

Tessa: we should be like fruit $\uparrow /$ [should we give (( )) names or fruit names?]

Assya: $[(())]$ talking to students in other table $\}$

Paola: ok / I'm gonna be \&

Assya: \& I'll be strawberry

Phebe: I should be \&

Eva: \& orange \{laugh

Tessa: I [will be]

?: $\quad[((\quad))]$

Assya: ((blackberry))

Paola: watermelon \{laugh $\} /[((\quad))]$

Tessa: I will be / kiwi (("chau"))

\{laughs

Eva: ((yes)) / you can see how we learn $\{$ laugh $\}$ 
Tessa: it was kiwi in Mandarin

55 Assya: kiwi \&

56 Paola: \& ((what did you last say?))

57 Assya: kiwi / kiwi / or kiwi / ( (( $)))^{\circ}$

$58 \quad$ Eva: /kiwi?/ (( )) /kiui?/

59 (...) $\left\{19^{\prime} 19^{\prime \prime}\right\}$

60 Eva: ah! \{sigh\} (2") I'm gonna fill it in // that's for sure

61 Tessa: stop saying that! / we're [are too good]

62 Paola: [is that how you learn?]

63 Tessa: we are [very good] $=$

64 Eva: [uh?]

65 Tessa: $=[$ in Mandarin $\uparrow]$

66 Paola: [is that how you learn?] / saying you're gonna fail \{laugh] \{talking to Eva\}

67 Tessa: [((you have to $))$ understand that we are perfect]

68 Eva: [I'm doing good / (( ) )]

69 Tessa: yeah / we get A staars / A / [that's it]

70 Paola: [((minus)) kiwi chau]

71 Eva: no

72 (...) $\left\{22^{\prime} 47^{\prime \prime}\right\}$

Eva: I'm gonna learn (3") I know Russian! [(( ))]

Alex: [half an] hour to go in this lesson / listen

Paola: fix this

Aaron: one or two areas / people engaging in / chit-chat / are not gonna make any progress / (( )) \& Eva: $\quad \&(\mathrm{I} \text { know })^{\mathbf{0}} \&$

Aaron: \& (( $)$ ) you need some suggestions \&

Eva: $\quad \&(((\quad)))^{\circ} \&$

Aaron: \& listen to / this / suggestion I have / I'm gonna pick on Alex ((I'm afraid)) // Alex has great phrases / three phrases / 你可以坐船去 (球场)) / next phrase / 你可以坐地铁去餐馆 / next phrase / 你可以坐公共汽车去狮子广场 / three phrases / three suggestions of things to do in London (4") how can you improve on what is done there? (2") Eva

Eva: we shouldn't repeat / sir

Aaron: yeah / slightly repetitive / anything else? / what could we do / it's lots of stuff in / you don't actually need to change those three phrases but what we need to do is to- to slot in / $((\{$ name? $\})) \uparrow$

?: $\quad(\text { add connectors / sir? })^{\circ}$

Aaron: add connectives! / so one would say / you can go to the / restaurant- you can take a taxi to the restaurant / THEN / you can go the- the / LATER / IN THE EVENING / you can go to thethe // ((so)) all together with / natural connectors / so make it not just like pu / pu / pu (4") but also / Omar

Omar: (your opinion) ${ }^{\circ}$

Aaron: ((put)) your opinion there! // you can take a taxi to go to the restaurant (3") I think that Chinese restaurants / [are / great]

[\{the girls on the table where the recorder is located laugh $\}]$

Aaron: remember / yeah? // you can also say / 我觉得英国的中国餐馆太贵 / it's too expensive / put a more- a higher level of opinion (()) don't just say 很好 / 很好 / 很好 / 很好 / 非常好 / 很好 \{someone on the girls' table laughs\}

Aaron: ((everyone gets what I'm saying))?

Eva: yeah

Aaron: these things can be slotted in quite easily with what you've done already / don't need to

Eva: so? ((scru:b it all out)) / work with what you've got now $\uparrow /$ carry on / that's 25 minutes

Paola: ok / now 
106 Eva: so what is your $((\quad))$ ?

107 Paola: ( ((what should it go in this place $)))^{\mathbf{o}}$

108 Assya: $((()))^{\mathbf{o}}$

109 Eva?: E:AST London

110 Assya?: [( east London $)^{\circ}$ ]

111 ?: [shh]

$112 \quad(10 ")$

113 Paola: $(())$

114 (20")

115 Paola: are you just copying it out?

116 Eva: uh?

117 Paola: are you just copying it out?

118 Eva: [what?]

119 Paola: [writing]

120 Eva: yeah / I need to write it on a little ((space)) so I can remember (2") $((\quad))$ ah $\{$ sigh $\} / / \mathrm{hhm}$

146 Assya?: imagine he can hear- image he- he can hear you

147 Eva: they can!

148 Assya: ((is it))?

149 Eva: they will listen to that after

150 Assya: oh my \&

151 Eva: \& why do you think they put that here? \&

152 Paola: \& (how can you guys do that?) ${ }^{\circ} \&$

153 Eva: \& it is $((\quad))\{$ laugh $\}$

154 Assya: yeah / [(( ))]

155 Paola: [how (( )) speak about children] (2") you are about to get deported (2") honestly they are / they're nice like that // that's (( ))

Assya: ok / ((I)) stop 
As a discursive space in which social action is constrained by institutional goals (i.e. curriculum and lesson plan) and dense social relations, analysis of one piece of classroom interaction often provides a window for identification of the relevant socio-institutional processes in the research site (Seedhouse 2004). In particular, Extract 7 offers a platform for exploration of two mutually-constitutive features that recurrently emerged during the process of data collection, namely, an institutional emphasis on highly controlled pedagogical designs on the one hand, and on the other, local forms of interpersonal collusion through which participants were able to deal with the anxiety involved in the teaching/learning of Chinese. This is evident in analysis of the sequential forms of social action (Erickson 1992) and participation frameworks (Goffman 1981) upon which the participants collaboratively construct the relevant frames of interpretation/action.

The emphasis on highly controlled pedagogical designs is played out in Aaron's attempts to set up a legitimate participation framework in which the students are expected to fill in the worksheet prepared by him through inserting a defined set of key vocabulary items. In other words, they are positioned as animators (Goffman 1981: 144) in that the required production format is that of voicing the lexical repertoire that he (author) has identified for them as the key for the final examination, both in Chinese written form and in the pinyin Roman transliteration, in order for them "not to have an excuse to fail" (Lines 2-14). The arrangement of the space and participation contributes to reinforce such an expected production format, with students sitting in groups and having their own Chinese-English dictionaries and notes from previous sessions so that they can support each other and complete the task successfully. Also, the presence of a teaching assistant, Carlos, facilitates the activity, so that both Aaron and Carlos can scaffold each group individually, when needed.

The emergence of interpersonal collusion in the local practice is particularly evident in the way the two teachers and the focal students engage with the proposed participation framework and make it sustainable in the moment-to-moment activity, even though many students have serious difficulties in fulfilling the task. Indeed, the course of the action shows a coordinated management of the frontstage and backstage of the scene (Goffman 1971: 114) that allows the two teachers and the focal students to deal with the overlapping of official and non-official tasks, which in turn solves the local concerns over participation in an activity that, although highly simplified by Aaron, might still be perceived by some students as too difficult or boring. This layering of the experience is co-constructed through joint turn-taking dynamics.

In the beginning of the session, Aaron explains the activity by using public floor signals and official expectations and obligations of the encounter (Lines 2-14). All students (and the teaching assistant) are positioned as both ratified hearers of Aaron in the dominant communication, or frontstage of the scene, and as participants of subordinate communication or byplays in the backstage - these subordinate exchanges are understood as "talk that is manned, timed, and pitched to constitute a perceivedly limited interference to what might be called the 'dominating communication' (Goffman 1981: 133). In fact, this proposed participation framework seems ratified by the rest of the participants in the course of the action, since they engage in the activity according to such expectations. Nevertheless, these byplays are expected to be delivered in a specific manner that is not followed by everyone, as signalled by Aaron in response to some groups' failure to comply with the rules - such as that of the focal students.

After setting up of the instructions, the focal group engages in continuous byplayed talk sequenced around assigning code names (Lines 16-58) and making jokes about how good they are in Mandarin (Lines 60-71), later being framed within Eva's discursive positioning as 
a frustrated learner through self-talk encouraging herself (Lines 60, 73). This is followed by a negative evaluation in which Aaron makes explicit the illegitimate nature of these byplays delivered in the shape of a "chit-chat" (Line 76). Although this evaluative contribution may function as a social form sanctioning the inappropriate participants in the activity, it seems to be primarily used by the teacher as a boundary-making practice to depart from the previous frame of action/interpretation, instead introducing pedagogical scaffolding, therefore framing the byplays of the focal students as an index of a lack of understanding of the task.

In particular, this evaluation is followed by a new sequence of explanation in which Aaron tries to further model the students' expected responses on their sheets (Lines 78-104). As in any other explanation in the classroom context, this new participation framework requires students to stop their subordinate forms of communication and listen attentively to the teacher's talk in the dominant communication, except for those who are explicitly heteroselected by the teacher, who are expected to contribute to the dominant communication by providing responses in turns (Mehan 1979, Cazden 1988, Tsui 1995). In doing so, Aaron manages to suggest the key information for the written task by leaning on the phrases used by Alex, one of the best students in the group. During this sequence there is also further room for ambivalent forms of collaboration displayed by Eva, the focal student who seems to be particularly concerned with the difficulty of learning Mandarin.

When the teacher is trying to shift to the new sequence of explanation, Eva seems to push the boundaries of what is acceptable by responding to Aaron in moments when his observations are not supposed to be qualified by the students (Lines 76-77). However, she speaks so softly that it is almost whispering, which softens the impact by backstaging it as a form of playful engagement. Indeed, this seems to be the teacher's interpretation - he does not provide any explicit evaluation and reacts by selecting Eva as the recipient of his question in the dominant communication, in what is another common procedure in the classroom context (Line 83). This is then followed Eva's collaboration, who provides a topically relevant answer (Line 84) which allows Aaron to develop the key highlights (with the help of two other students who are later selected by the teacher) on the importance of avoiding repetition by inserting connectives in the above-mentioned three phrases and using formulaic expressions to give personal opinions (Lines 85-95).

Immediately after the second student's contribution to the public floor, Aaron's explanation overlaps with laughter from the focal group (Lines 94-96). This is followed by another exchange in which Eva responds to the teacher's question checking the whole class's comprehension with what could be interpreted as a further instance of collaboration (Lines 101-102). This interpretation seems to be reinforced by subsequent actions and reactions, since the teacher's request for all students to get back to work is followed by Eva's attempts to do the activity by relying on byplay with her group of peers (Lines 105-121). From this point to the end of the extract, however, Eva and her peers continue engaging in a pattern of participation that is similar to what they produced before Aaron's explanation, and this allows them to partially fill in some of the required information within the frame of an enjoyable conversation focused on the sharing of more learning frustrations (Line 122), mocking the teaching assistant (Line 127-128), yawning (Line 129), code-name giving (Lines 131-137) and looking for bad words in the Chinese dictionary (Lines 139-158).

In sum, analysis of Extract 7 provides a window on the local (pedagogical and interpersonal) strategies being recurrently used by the students and teachers in the Chinese classes at ELS, in order to deal with the institutional tensions associated with teaching and learning of Mandarin. While all of them seemed to gain from investing in this language, due to the subsequent access that it provided to relevant social categories such as "good school/division/student", they needed to engage in the pedagogical and interactional 
construction of "safe houses" (Canagarajah 1997). Through interactional forms of "collusion" (Mc Dermott \& Tylbor 1986), these spaces allowed them to construct the fiction of a successful implementation of the programme under conditions in which the institutional expectations were hard to fulfil. Indeed, most of the students in Years 10 and 11 stated in their questionnaires that they were not willing to continue learning Mandarin after GCSE "too difficult" was the most recurrent reason provided.

\section{Language-in-education policy and practice in late modernity}

In his attempts to develop a sociolinguistics of globalization, Blommaert (2010) invited us to move away from the traditional focus on stable and homogeneous speech communities and "to consider situations in which various 'big' sociolinguistic systems enter the picture" (2010: 41). He drew sociolinguists' attention to the fact that under globalization, people do not just move across spaces but also across different "orders of indexicality", meaning different patterns of normativity applying to the same given semiotic space, which makes communication less predictable. Indeed, this seems to be the case at ELS in that its discursive organization as a social institution is shaped by its symbolic positioning at the intersection of local, national, regional and global policies/discourses that include different institutional agencies such as the British Council, the EU and the Hanban office, each linked with different histories and constitutive semiotic constellations (i.e. configurations of desirable social categories and normative forms of social interaction).

Such a symbolic positioning has specific consequences for the articulation of the socioideological, institutional and interaction orders of the school (including the linguistic and the moral orders). In particular, the implementation of the Chinese Division at ELS, and its status as a Confucian Classroom, brings about a re-definition of the normative categories upon which the school social life is structured. In other words, the social constitution of what counts as a "good" school, division, student, or appropriate forms of knowledge in the classroom, gets redefined by a new logic of value attribution/circulation because of entry of the new stakeholders (and their discourses/policies). On the one hand, the Chinese division allows the school to engage with institutional narratives focused on competitions, rankings, internationalization and academic excellence in a working-class area. This generated a specific indexical meaning - that of being a "good school" - in the discursive frame set up by the policies of British Council and EU in which globalization, linguistic instrumentalism and social cohesion are emphasized.

On the other hand, the Mandarin section causes concerns and dilemmas derived from the overlapping of two additional orders of indexicality, one tied with the space of foreign language learning in the UK and another linked to the requirements and expectations from Hanban. The space of foreign language learning in the UK is traversed by a) the dominance of French as a traditionally institutionalized regional language; and b) continuing downward trend in the number of students studying languages as part of compulsory education because of their lack of interest in the traditionally institutionalized languages in Europe. Thus, the competition over access to learners in a language specialist school such as ELS, in which French has a privileged position, pushes the Chinese section to discursively construct itself as "desirable" through emphasis on cultural uniqueness, academic distinctiveness and fun learning.

The partnership between Hanban and the British Council, and the subsequent extrafunding, place the Hanban in a position to shape decisions on what counts as appropriate or legitimate knowledge in the Chinese classes. This is done through a logic in which Hanban 
gets an active role in the institutional design and monitoring of assessment, which in turn has a direct impact on curriculum and instruction. In particular, the active role of Hanban in assessment brings about an institutional frame of (historical) normative expectations (described elsewhere in relation to an institutional culture of education in China) in which high demands for vocabulary memorization of written characters plays a key role. So this frame pushes the teaching and learning of Chinese in the school towards emphasis upon a number of compulsory characters that have to be mastered at the end of every year for the Chinese division to fulfil Hanban's expectations.

These tensions arising from the normative expectations associated with each of these two orders of indexicality, in which one pushes the organization of the Chinese division towards the principles of fun and difference while the other gives more prominence to routine and memorization, increasingly disempower the teachers and students involved. The overlapping of these orders of indexicality under the conditions of a local system heavily oriented to competition, efficiency, excellence and internationalization results in highly controlled pedagogical designs and interaction practices of collusion. Through these designs and practices, students and teachers manage to deal with the contradiction of having to teach and learn a language that, although a key capital for the school as a whole (and for each of them individually), is invested with institutional expectations that are hard to meet.

In sum, the story of ELS allows us to track the institutional tensions brought about by the socioeconomic conditions of late modernity. Institutional neoliberalization (i.e. selective deregulation and internationalization), shifts in the utility of language learning underlying the second-language education policies (i.e. institutionalization of global languages with no regional or ethno-national roots in one territory), and the progressive destabilization of traditional relationships between students and teachers (i.e. teachers as powerful representatives of the state) seem to apply to the data analyzed in this article. The combination of these dimensions is reflected in the increasing transnationalization of new stakeholders such as Hanban, which does not fit easily into a modernist institutional architecture. In contrast to the language education policies of the modern nation-state, this panorama opens up new discursive terrain for the "polycentric" (Blommaert 2010: 39) articulation of norms and perceived appropriateness to which institutions have to adjust. It has yet to be seen how the dilemmas described here are dealt with in the years to come. 


\section{Appendix: Symbols used in the transcripts}

$\begin{array}{ll}\text { Laura: } & \text { participant } \\ \text { CR } & \text { (Capital letters) loud talking } \\ \text { ee } & \text { vowel lengthening } \\ \text { Ss } & \text { consonant lengthening } \\ / & \text { short pause }(0.5 \text { seconds }) \\ / / & \text { long pause }(0.5-1.5 \text { seconds }) \\ (\mathrm{n} ") & \text { n seconds pause } \\ {[\quad]} & \text { turn overlapping with similarly marked turn } \\ = & \text { continuation of utterance after overlapping } \\ (()) & \text { non-understandable fragment } \\ \{\text { xxx }\} & \text { researcher's comments } \\ \uparrow & \text { rising intonation } \\ \downarrow & \text { falling intonation } \\ - & \text { self interruption } \\ \& & \text { latched utterances }\end{array}$

\section{References}

Berger, P. \& Luckmann, T. (1991). The social construction of reality. London: Penguin Books.

Blackledge, A. \& A. Creese (2010). Multilingualism. London: Continuum.

Blommaert, J. (2010). The Sociolinguistics of Globalization. Cambridge: Cambridge University Press.

Blommaert, J. \& Rampton, B. (2011). Language and superdiversity. Diversities 13 (2), 1-23.

British Council (2013). Languages for the Future Report. Retrived from: http://www.britishcouncil.org/sites/britishcouncil.uk2/files/languages-for-the-futurereport.pdf

Canagarajah, A.S. (1997) "Safe Houses in the Contact Zone: Coping Strategies of African American Students in the Academy." College Composition and Communication 48 (2), 173-196.

Cazden, C. B. (1988). Classroom Discourse: The Language of Teaching and Learning. Portsmouth, NH: Heinemann.

Cicourel, A. (1973). Cognitive Sociology: Language and Meaning in Social Interaction. London: Penguin.

Cicourel, A. (1980). Three models of discourse analysis: The role of social structure.

Discourse Processes 33, 101-132.

Cicourel, A. (1992). The interpenetration of communicative contexts: Examples from medical encounters. In: Goodwin, Charles \& Alessandro Duranti (eds), Rethinking Context: Language as an Interactive Phenomenon (pp. 291-310). Cambridge: Cambridge University Press.

CILT (2005, 2008, 2010). The National Centre for Languages. Annual Report: http://www.cilt.org.uk/home/about_us/financial_and_annual_reports.aspx.

Cortazzi, M. \& J. Lixian (1997). Cultures of learning: Language classrooms in China. In: H. Coleman (Ed.), Society in the Classroom (pp. 169-206). Cambridge: Cambridge University Press.

Council of Europe (2007). From linguistic diversity to plurilingualism: Guide for the development of language education policies in Europe. Strasbourg. 
Council of Europe (2008), Recommendation on the use of the Council of Europe's Common European Framework of Reference for Languages (CEFR) and on the promotion of plurilingualism. Strasbourg.

Duchêne, A. \& Heller, M. (Eds) (2012). Language in Late Capitalism: Pride and Profit. New York: Routledge.

Erickson, F. (1992). Ethnographic Microanalysis of Interaction. In: M. LeCompte, W. Millroy \& J. Preissle (Eds.), The Handbook of Qualitative Research in Education (pp. 201-225). New York: Academic Press.

European Commission. (2008). Multilingualism: An asset for Europe and a shared commitment. COM (2008) 566. 18/09/2008. Brussels.

European Commission (2012). Key Data on Teaching Languages at School in Europe 2012. Brussels.

Fenoulhet, J., Ros \& Sole, C. (Eds.) (2011). Mobility and Localisation in Language Learning. A View from Languages of the Wider World. Oxford: Peter Lang.

Goffman, E. (1974). Frame Analysis: An Essay in the Organization of Experience. New York: Harper \& Row.

Goffman, E. (1981). Forms of Talk. Philadelphia: University of Pennsylvania Press

Harris, R. \& B. Rampton (2009). Ethnicities without guarantees: an empirical approach. In: M. Wetherell (Ed.), Identity in the $21^{\text {st }}$ century: New Trends in Changing Times. Basingstoke: Palgrave.

Heller, M. (2007). Distributed knowledge, distributed power: A sociolinguistics of structuration. Text \& Talk 27(5/6): 633-653.

Heller, M. \& M. Martin-Jones (Eds.) (2001). Voices of Authority. Education and Linguistic Difference. AblexPublishing, Wesport/Connecticut/London.

Krzyzanowski, M., \& Wodak, R. (2011). Political strategies and language policies: The European Union Lisbon strategy and its implication for the EU's language and multilingualism policy. Language Policy, 10, 115-136.

Li Wei (2013). Negotiating funds of knowledge and symbolic competence in the complementary school classrooms. Language and Education 28 (2), 161-180.

Li Wei \& Zhu Hua (2013). Translanguaging identities: Creating transnational space through flexible multilingual practices amongst Chinese university students in the UK. Applied Linguistics 34 (5), 516-535.

Lorenzo, F., \& Moore, P. (2009). European language policies in monolingual Southern Europe: Implementation and outcomes. European Journal of Language Policy 1(2), 121-135.

McPake, J., Sachdev, I., Carroll, T., Birks, T. \& Mukadam, A. (2008). Final report: Community Languages in Higher Education: Towards realising the potential. Southampton: Routes into Languages.

Martín-Rojo, L. (2010). Constructing Inequality in Multilingual Classrooms. Mouton, Berlin.

Mehan, H. (1979). Learning Lessons: Social Organization in the Classroom. Cambridge, MA: Harvard University Press.

Moore, R. (2011). Standardisation, diversity and enlightenment in the contemporary crisis of EU language policy. Working papers in language \& literacies, 74.

Pérez-Milans, M. (2013). Urban Schools and English Language Education in Late Modern China: A Critical Sociolinguistic Ethnography. New York \& London: Routledge.

Rampton, B. (2006). Language in Late Modernity. Interaction in an Urban School. Cambridge: Cambridge University Press.

Roberts, C. (2009). Institutional Discourse. In: The Routledge Companion to English Language Studies (pp. 181-195). 
Romaine, S. (2013). Politics and policies of promoting multilingualism in the European Union. Language Policy 12, 115-137.

Said, E. (1978). Orientalism. New York: Pantheon.

Sarangi, S. \& Slembrouck, S. (1996). Language, Bureaucracy and Social Control. London: Longman.

Seedhouse, P. (2004). The Interactional Architecture of the Language Classroom: A Conversation Analysis Perspective. Oxford: Blackwell.

Smith, D. (2005). Institutional Ethnography: A Sociology for People. Lanham, MD: Altamira Press.

Tsui, A. B. M. (1995). Introducing Classroom Interaction. London: Penguin.

Wodak, R. (2007). 'Doing Europe': The discursive construction of European identities. In: R. C. M. Mole (Ed.), Discursive constructions of identity in European politics (pp. 7095). Basingstoke: Palgrave.

Zhu Hua \& Li Wei (2014). Geopolitics and the changing hierarchies of the Chinese language: Implications for policy and practice of Chinese language teaching in schools in Britain. Modern Language Journal 98 (1), 326-339. 